\title{
AN ASSESSMENT AND COMPARISON OF THE SENSITIVITY OF VARIOUS MACROETCHES
}

FOR ALLOY 718

\author{
T. Le Roux* and D.A. Wells** \\ *Inco Alloys Limited \\ Holmer Road \\ Hereford, U.K. HR4 9SL \\ *:Inco Alloys International, Inc. \\ P. 0. Box 1958 \\ Huntington, West Virginia 25720
}

\begin{abstract}
Companion laboratory-scale studies were conducted on specimens of ESR alloy 718 in order to determine responsiveness of this material to several of the macroetching techniques used in the industry. The work developed from initial efforts to define the relative sensitivity to Alloy 718 segregation of the macroetchants in standard use at the respective locations of Inco Alloys International: one an electrolytic etch using a 50\% solution of concentrated $\mathrm{HCl}$ in water, followed by an electrolytic stain performed in'a $4 \% \mathrm{H}_{2} \mathrm{SO}_{4}$ solution; the other an immersion etchant using a water solution of $\mathrm{H}_{2}^{2} \mathrm{O}_{2}{ }^{4}$ and concentrated $\mathrm{HCl}$. Other etchants included in the resulting study were Canada's, Heppenstall, and one containing ferric chloride.

These studies showed that the HCl electrolytic etch technique possesses the greatest sensitivity to variations in segregation, and that the water/HCl/Peroxide immersion technique showed the least sensitivity. The others were found to fall between these two poles.

Aside from immediate implications for the Inco Alloys International locations involved, there appear to be larger questions for the industry as a whole concerning relative etch responses and standards for assessment of matcrial etched by the various techniques. There are potentially stronger implications for VAR material because of its greater vulnerability to white spot, a key feature which was not observed in the ESR samples studied here.
\end{abstract}




\section{Introduction}

Macroetching of billet slices allows assessment of the material for a variety of segregation types. Evaluations of alloy 718 etch slices focus on dark-appearing concentrations of carbides or other phases formed from elements such as niobium (freckles and interdendritic segregation), and on light-appearing regions depleted in same (white spots), and on the severity of "rings" (which indicate variations in progress of the freeze front). In general it can be said that the aerospace industry does not demand that suppliers use specified methods for macroetching. As a result, melt sources and forgers have devised their own etchant compositions and the techniques for using them. Etchants can vary in their sensitivities to the different types of segregation, and each alloy tends to react in its own particular way to each etchant. These variables can make it very difficult to directly compare the segregation present in slices etched by different methods. Compounding this picture is the fact that standards used for assessment can also vary, though there are widely-accepted criteria in use.

The issue of variability in macroetch response was clearly highlighted for representatives of the two Inco Alloys International Technology units who met at Inco Alloys Ltd. for a melting conference in the spring of 1987. A slice of ESR melted alloy 718 had been given the standard Inco Alloys Internationa1, Inc. macroetch, and appeared to have acceptable levels of segregation. Inco Alloys Ltd. personnel reprepared and etched a part of that slice per the standard method there. Its appearance with respect to interdendritic dark-etching spots and ring pattern was considerably less attractive after that second etch than it had been after the first.

Further investigations were initiated to determine where other etchants used in the industry might be situated relative to these two regarding sensitivity to alloy 718 segregation.

\section{Experimental Details}

Inco Alloys Ltd.

The work in Hereford focused primarily on evaluating the etchants' sensitivities to interdendritic segregation.

Three transverse slices were taken from a nominal $335 \mathrm{~mm}$ diameter har which had been forged from a $540 \mathrm{~mm}$ diameter VIM+ESR ingot of alloy 718 at Inco Alloys Ltd. (See chemical composition for this ingot in Table I.) These slices represented material from the top, middle and bottom locations of this ingot, which was a development melt and not typical of standard production with respect to melt rate.

Each slice had exhibited a distinct severity level of interdendritic segregation after macroetching per the HCl electrolytic method. These known differences in severity of center "black spot" among the slices served as the basis for comparing relative sensitivities of etchants to interdendritic segregation, possibly the type of macrosegregation in alloy 718 which is the most diffusc and difficult to quantify.

Four nominal $50 \mathrm{~mm}$ square blocks were cut from the central portion of each slice per the pattern shown in Figure 1-a). This sampling method captured equivalent portions of interdendritically segregated material for the comparison work. 'lhese squares were then identified " $\mathrm{A}$ ", "B", " $\mathrm{C}$ ", and " $D$ ". The surface of each square was prepared by machine grinding. The " $A$ " square from each slice was exposed to the "Ferric Chloride" ctch method; the "B" squares to Canada's; "C" squares to Heppenstal1; and "D" squares to 
"3:2:1". (Parts A to D of Table II describe the etchanl compusitions and procedures used.) The squares were evaluated and photographs taken.

These etched surfaces were reprepared by machine grinding, then all were reetched and stained per the $50 \% \mathrm{HCl} / 4 \% \mathrm{H}_{2} \mathrm{SO}_{4}$ electrolytic method (see Table II E). Photographs were taken of each square. Final evaluations and comparisons of etch response were then made.

Table I. Chemical Composition (wt. \%) of ESR Ingots Sampled

\begin{tabular}{|c|c|c|c|c|c|c|c|c|c|}
\hline Heat No. & $\mathbf{C}$ & Fe & Si & $\mathbf{N i}$ & Cr & A1 & $\mathbf{T i}$ & Mo & $\mathrm{Nb}+\mathrm{Ta}$ \\
\hline \multicolumn{10}{|c|}{ (Inco Alloys Ltd.) } \\
\hline JLH0216 & 0.035 & 17.8 & 0.18 & 53.43 & 18.76 & 0.54 & 1.01 & 3.02 & 5.11 \\
\hline \multicolumn{10}{|c|}{ (Inco Alloys International, Inc.) } \\
\hline VT0023EK & 0.023 & 16.6 & 0.08 & 54.11 & 19.12 & 0.56 & 1.00 & 3.03 & 5.36 \\
\hline
\end{tabular}

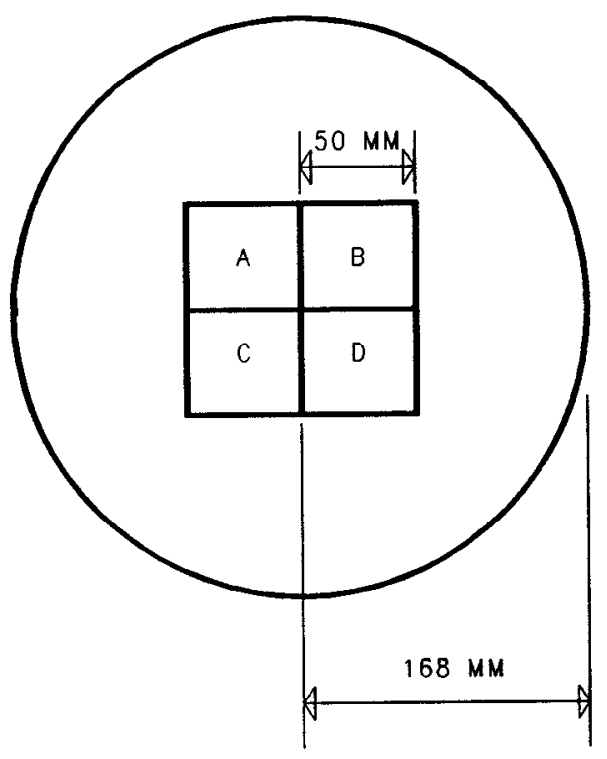

a)

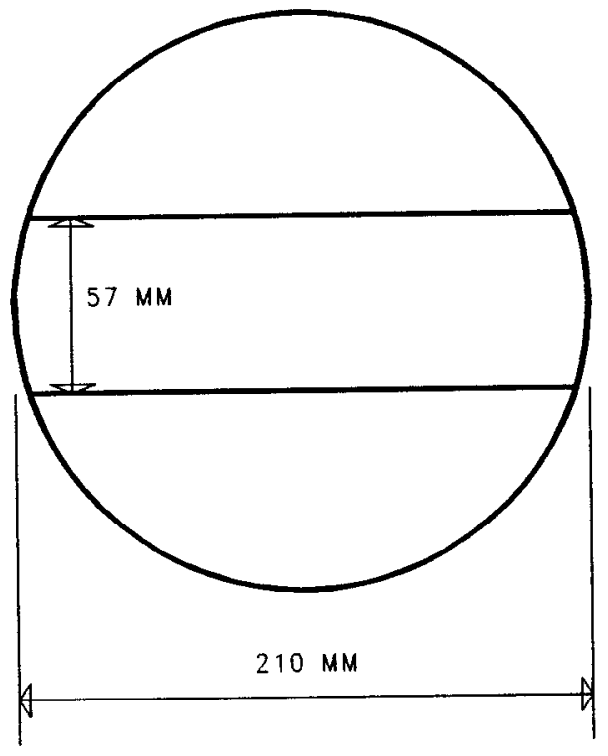

b)

Figure 1 - Sampling pattern for etch specimens:

a) Squares cut from 3 transverse slices (Inco Alloys Ltd.),

b) Strip cut from one transverse slice (Inco Alloys International, Inc.). 
Table II. Compositions of Etchants Used, and Comments on Techniques

\begin{tabular}{|c|c|c|}
\hline $\begin{array}{l}\text { ETCHANT } \\
\text { CODE and NAME }\end{array}$ & $\begin{array}{l}\text { NOMINAL } \\
\text { COMPOSITION }\end{array}$ & ETCHING TECHNIQUE USED \\
\hline $\begin{aligned} \text { A - } & \text { "Ferric } \\
& \text { Chloride" }\end{aligned}$ & $\begin{array}{l}75 \% \text { conc } \mathrm{HCl} \\
21 \% \mathrm{FeCl}_{3} \\
3.5 \% \text { conc } \mathrm{HNO}_{3}\end{array}$ & $\begin{array}{l}\text { "Activate" the slice by immersing } \\
\text { it for } 5-10 \text { minutes in } 50 \% \text { conc } \\
\text { HCl in hot water. Transfer the } \\
\text { slice to the "Ferric Chloride" } \\
\text { etch for a nominal } 45 \text { minutes. } \\
\text { Swab with a cloth rag as needed to } \\
\text { make the stain less dense. }\end{array}$ \\
\hline B - Canada's & $\begin{array}{ll}8 & \text { parts } \mathrm{H}_{2} \mathrm{O} \\
2 & \text { parts conc } \mathrm{H}_{2} \mathrm{SO}_{4} \\
2 & \text { parts conc } \mathrm{HF}_{4} \\
1 & \text { part conc } \mathrm{HNO}_{3} \\
\end{array}$ & $\begin{array}{l}\text { Slice and etchant are both lo be } \\
\text { hotter than } 70^{\circ} \mathrm{C} \text {. Remove slice } \\
\text { when piece darkens (no set time of } \\
\text { exposure). Rinse and dry. }\end{array}$ \\
\hline C - Heppenstall & $\begin{array}{l}3 \text { parts } \mathrm{H}_{2} \mathrm{O} \\
2 \text { Parts conc } \mathrm{HCl} \\
1 \text { part } \mathrm{H}_{2} \mathrm{O}_{2} \\
(35 \% \text { wt } \%)\end{array}$ & $\begin{array}{l}\text { Preheat slice in hot water, then } \\
\text { immerse in etchant. Remove when } \\
\text { surface darkens. Rinse and dry. }\end{array}$ \\
\hline$D-" 3: 2: 1 "$ & $\begin{array}{l}3 \text { parts } \mathrm{H}_{2} \mathrm{O} \\
2 \text { parts conc } \mathrm{HCl} \\
1 \text { part } \mathrm{H}_{2} \mathrm{O}_{2} \\
(35 \text { wt } \%)\end{array}$ & $\begin{array}{l}\text { Preheat the sample in hot water. } \\
\text { Immerse slice in etchant. Take } \\
\text { from bath when bath reaction } \\
\text { stops. (Re-expose if response is } \\
\text { incomplete.) Wipe surface, rinse } \\
\text { and dry. }\end{array}$ \\
\hline $\begin{aligned} E- & 50 \% \mathrm{HCl} \\
& \text { Electrolytic }\end{aligned}$ & $\begin{array}{l}1 \text { part conc } \mathrm{HCl} \\
1 \text { part } \mathrm{H}_{2} \mathrm{O}\end{array}$ & $\begin{array}{l}\text { Preheat the slice in hot water. } \\
\text { Place slice on anode plate in the } \\
\text { solution. Slightly immerse cath- } \\
\text { ode in solution over slice. Use } \\
\sim 0.75 \mathrm{~A} / \mathrm{cm}^{2} \text {. Etch for } 3 \text { to } 6 \\
\text { minutes. Remove, rinse and } \mathrm{dry} \text {. } \\
\text { Stain electrolytically in } 4 \% \mathrm{H}_{2} \mathrm{SO} 4 \\
\text { at } 0.1 \mathrm{~A} / \mathrm{cm}^{2} \text { for } 3 \text { seconds. } \\
\text { Rinse and dry. }\end{array}$ \\
\hline $\begin{aligned} F- & \text { Modified } \\
& \text { SNECMA } \\
& \text { "Dark Etch" }\end{aligned}$ & $\begin{array}{l}8 \text { parts } \mathrm{FeCl}_{3} \\
\text { sol'n }\left(\mathrm{s} \cdot \mathrm{g} \cdot \mathbf{1}^{-45)}\right. \\
1 \text { part conc } \mathrm{HCl} \\
1 \text { part } \mathrm{H}_{2} \mathrm{O}\end{array}$ & $\begin{array}{l}\text { Preheat the slice. Immerse in } \\
\text { etchant at nominal } 60^{\circ} \mathrm{C} \text {. Remove } \\
\text { after } 20 \text { minutes and rinse. Dry } \\
\text { with blown air. }\end{array}$ \\
\hline
\end{tabular}


Inco Alloys International, Inc.

The effort in Huntington was focused on evaluating differences in etch response across a transverse section. It continued with that one piece electrolytically etched during the melting conference in Hereford because Huntington's lab is not equipped for electrolytic etching on such a scale.

The sample used was a $57 \mathrm{~mm}-$ wide strip from the center of a transverse etch slice. That parent slice had been cut from the position on a nominal $210 \mathrm{~mm}$ diameter bar which corresponded to $1 / 4$ of the way down from the ingot top. The location of the sample strip in its parent slice is shown in Figure 1-b). The bar itself had been processed from a nominal $430 \mathrm{~mm}$ diameter ESR ingot. (See chemical composition of the material in Table I.)

'l'his strip was etched per each of the methods shown in Table II. It was evaluated and photographed after each one and was resurfaced by machine grinding between etch exposures. Comparisons of the responses to these etchants were made on the basis of notations and photographic records.

\section{Data Review}

Sensitivity of Etchants to Interdendritic Segregation (Inco Alloys Ltd.)

"Ferric Chloride" (A). The "a)" parts of Figures 2, 3 and 4 show the response of squares etched in the "Ferric Chloride" etchant. It was a sufficiently stable etchant for all of the squares to be processed through the same batch. The earliest visible effect during etching was the emergence of grain pattern after about 6 minutes. It required 30 minutes or more for the irterdendritic segregation to emerge, and gave clear evidence of its presence only in the square taken from the "top" slice [Figure 2a)].

Canada's (B). See part "b)" of Figures 2, 3 and 4 for results of exposing squares to Canada's. This etchant also was stable, though extra operating precautions were required because of the temperature and $\mathrm{HF}$ acid content. The squares responded quickly to Canada's, clearly revealing dendritic pattern and black spots within about ten minutes.

Heppensta11 (C). Shown in part "c)" of Figures 2, 3 and 4 are the appearances of squares etched in the Heppenstall solution. It, like Canada's, responded quickly, revealing segregation within approximately ten minutes. It also required precautions. Unlike Canada's, however, this etch produced uneven and "patchy" results, and appeared to behave inconsistent $1 y$.

3:2:1" (D). The "d)" portions of Figures 2, 3 and 4 carry results of exposing squares to "3:2:1" in the manner prescribed in Table II. The etch responses of its squares were the least definitive of all, though roughly comparable to those for the "Ferric Chloride" etch.

50\% HCl Electrolytic (E). All squares from all of these slices were etched by this method. Results are shown in photographs on the outside of quadrants a) through d) in Figures 2, 3 and 4. This etchant's definition for all interdendritic segregation severities was clearly superior to that of both "Ferric Chloride" and "3:2:1". It was generally comparable in definition to Canada's and Heppenstall etches. However, it provided more consistent and/or marginally sharper contrast for the black spots when samples from all levels of segregation intensity are taken into account. 


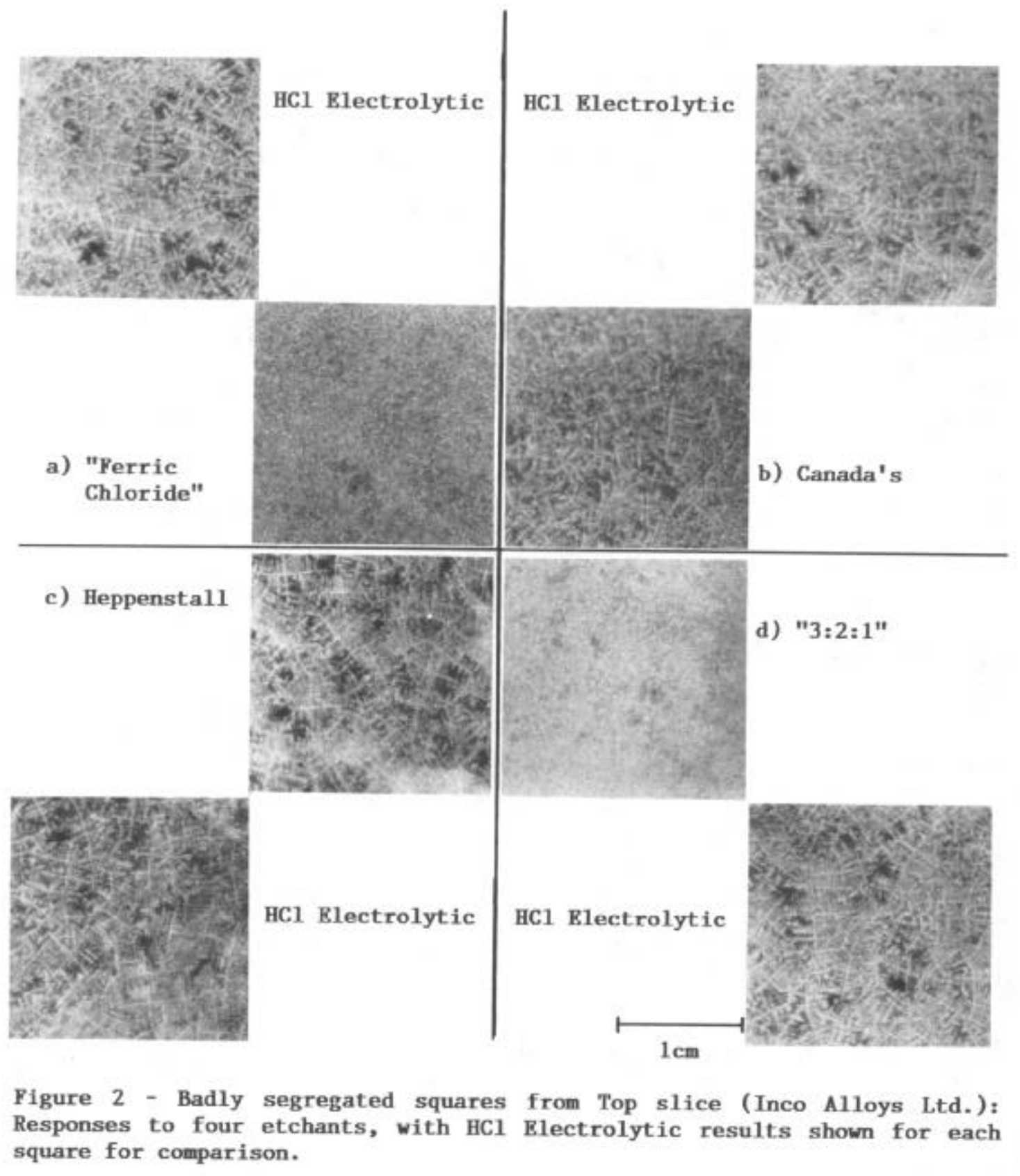

Sensitivity of Etchants Across a Section (Inco Alloys International, Inc.)

Figure 5 displays results of exposing the one strip sample to various etchants, machine grinding the piece to a nominal 25 RMS finish before each. It can be generally stated that the etchant characteristics noted above were consistent with those observed during the etchings of this piece, with small differences in times required to obtain desired responses. The above-noted "instability" of the Heppenstall etch was such that the first attempt to use it on this strip yielded no definition of any segregation type. A second attempt produced the response shown in Figure 5c). The piece appeared to show more interdendritic segregation while it was still in the etchant than it did after it had been removed. 


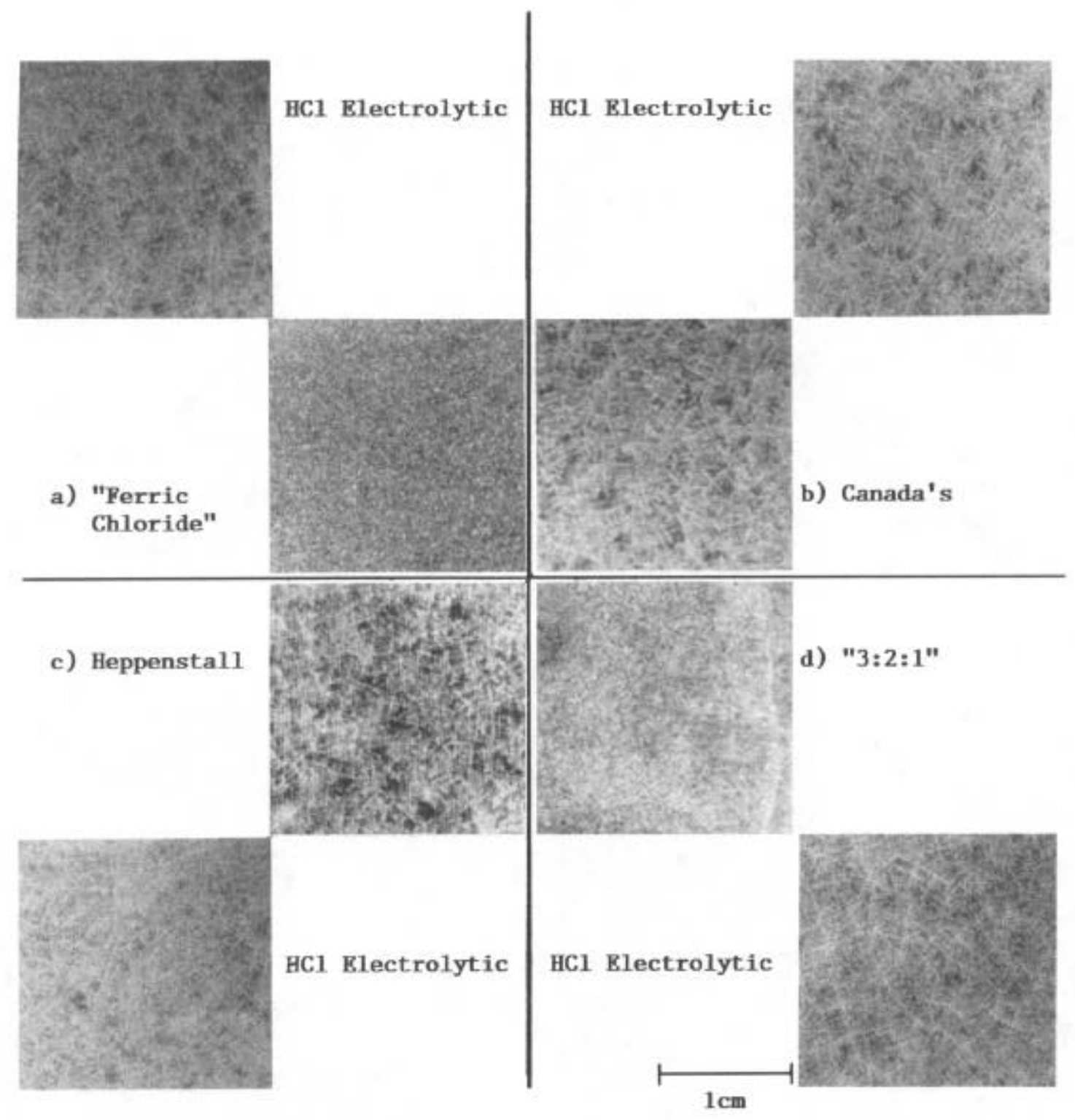

Figure 3 - Moderately segregated squares-Middle slice (Inco Alloys Ltd.): Responses to four etchants, with HCl electrolytic results shown for each for comparison.

Part f) of Figure 5 shows the response of this piece to the SNECMA "dark etch", modified in composition as shown in Table II-F. (The squares above were not exposed to this etch.)

The sharpness of definition for dendritic areas typical for the HC1 electrolytic etch [center of Figure 5-e)] extends to the ring pattern [edge of Pigure 5-e)]. The other etchants did not reveal the ring pattern in this sample. In addition, definition of black spots by the electrolytic etch was clearly sharper than that which had been produced by exposure of the sample to any of the other etchants, including Canada's and Heppensta11. There was no ambiguity in result at that point on this sample like there had been in the case of the squares. 


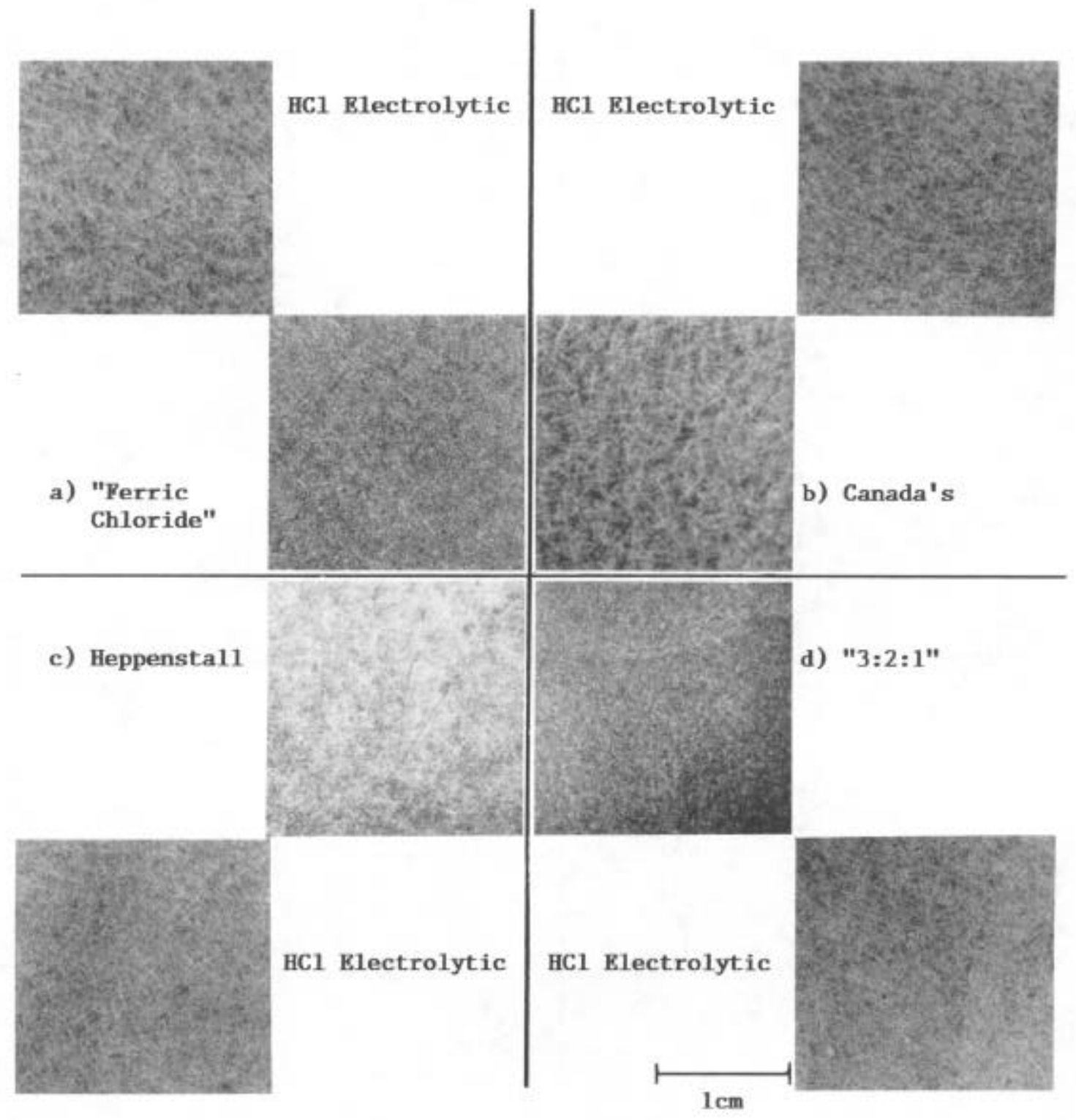

Figure 4 - Lightly segregated squares-Bottom Slice (Inco Alloys Ltd.): Responses to four etchants, with HCl electrolytic results shown for each for comparison.

Under some conditions, such as the etching of an annealed alloy 718 slice, "3:2:1" will produce a non-adhering dark film. As long as the film does remain on the surface, though, it highlights the dark and white spots and tree ring segregations similarly to the way Canada's does. The samples had not been annealed for either of these experiments. As a result, no such film was observed on any of the samples described here. This unpredictability of etch response gives the user of "3:2:1" no confidence that there will be any discernable definition of any segregation type. 


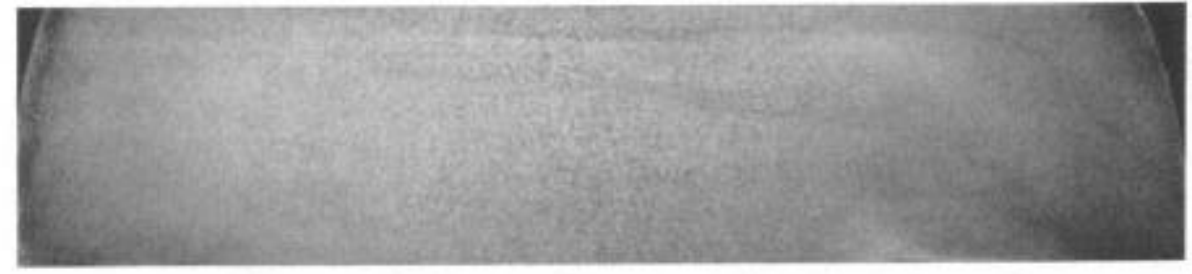

a)

"Perric

Chloride"

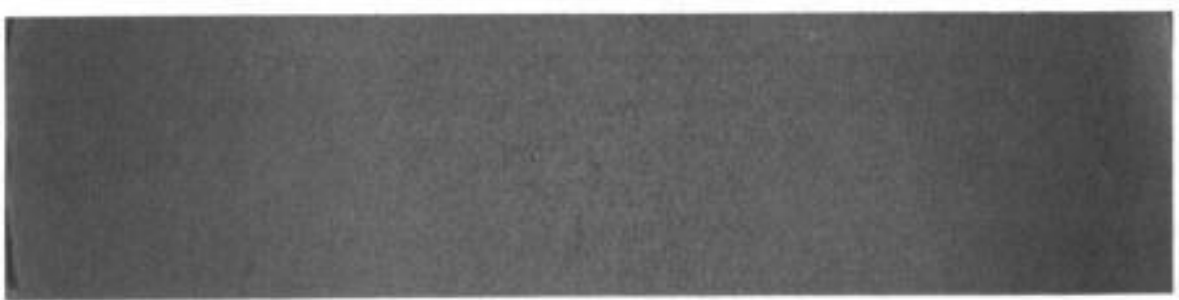

b)

Canada's

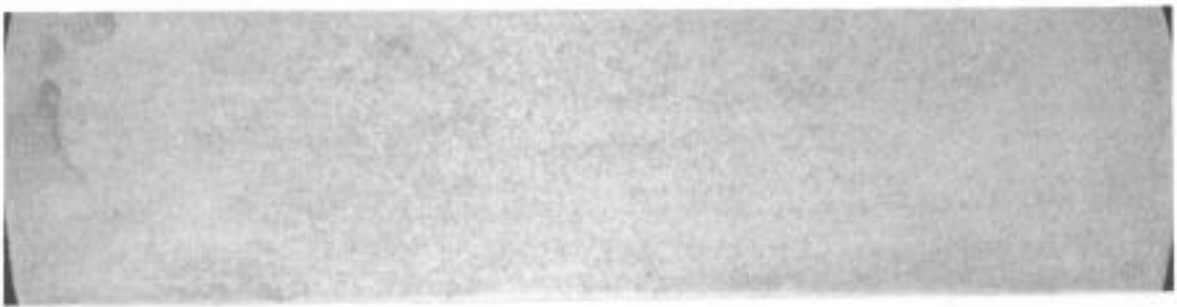

c)

Heppensta11

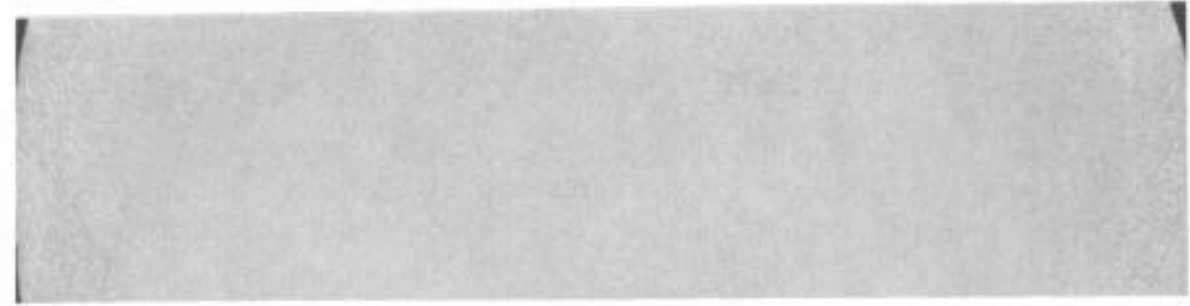

d)

"3:2:1"

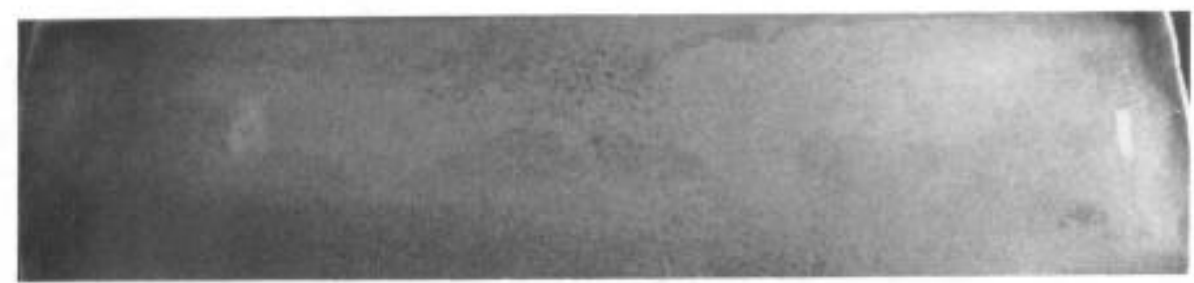

e)

$50 \mathrm{z}$ HC1

Rlectrolytic

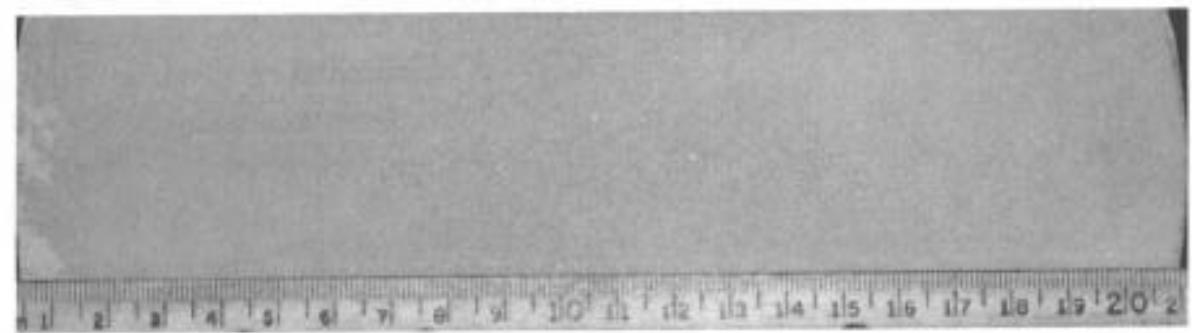

f)

Modified

SNECMA

"Dark Etch"

Figure 5 - Appearance of strip sample after etching per techniques named beside each photograph (Inco Alloys International, Inc.). 
of the etch techniques used in these experiments, the HCl electrolytic etch more consistently provided clear distinctions among degrees of interdendritic segregation in alloy 718. It also revealed the tree ring pattern in the strip sample, while the other etchants did not. (Please note that the 1ight smudges on Figure 5-e) are simply marks picked up in hand1ing at the two Inco Alloys International labs and in transit.)

Canada's etch performed reliably and reproducibly, though at the cost of some added precautions for users who are not accustomed to working with hot solutions containing $\mathrm{HF}$ acid. It was very comparable in response to the $\mathrm{HCl}$ Electrolytic etch regarding interdendritic segregation.

Heppenstall etch produced good definition of interdendritic segregation when these users were able to get this seemingly unpredictable technique to work.

Though "Ferric Chloride" and "3:2:1" had paralleled one another in etch response on the squares above, "Ferric Chloride" produced the better response on this strip sample [compare Figures 5-a) and 5-d)].

A modified SNECMA "Dark Etch" was used only on the strip section sample. It defined very little of the interdendritic segregation. There were evidently no white spots available for it to highlight.

The "3:2:1" etch performed weakly in both experiments on as-produced material, demonstrating an ability to reveal only the worst cases of interdendritic segregation.

\section{Conclusion}

The alloy 718 industry may wish to take note of the observations presented in these studies. Although etch techniques are well established with their users, these experiments have concluded that all are not equally effective. 